\title{
The novel complex combination of alum, CpG ODN and HH2 as adjuvant in cancer vaccine effectively suppresses tumor growth in vivo
}

\author{
Yaomei Tian ${ }^{1,}{ }^{*}$, Meng Li $^{2,}{ }^{*}$, Chaoheng Yu ${ }^{1}$, Rui Zhang ${ }^{1}$, Xueyan Zhang ${ }^{1}$, Rong Huang ${ }^{1}$, \\ Lian Lu ${ }^{1}$, Fengjiao Yuan ${ }^{1}$, Yingzi Fan ${ }^{1}$, Bailing Zhou ${ }^{1}$, Ke Men ${ }^{1}$, Heng Xu ${ }^{1}$ and Li Yang ${ }^{1}$ \\ ${ }^{1}$ State Key Laboratory of Biotherapy, West China Hospital, Sichuan University and Collaborative Innovation Center, Chengdu, \\ Sichuan, China \\ ${ }^{2}$ Chengdu Blood Center, Chengdu, Sichuan, China \\ *These authors have contributed equally to this work
}

Correspondence to: Li Yang, email: yl.tracy73@gmail.com

Keywords: combinatorial adjuvant, aluminum salts, CpG oligodeoxynucleotide, innate defense regulator peptide HH2, anti-tumor immune responses

Received: December 07, $2016 \quad$ Accepted: April 02, 2017 Published: April 28, 2017

Copyright: Tian et al. This is an open-access article distributed under the terms of the Creative Commons Attribution License 3.0 (CC BY 3.0), which permits unrestricted use, distribution, and reproduction in any medium, provided the original author and source are credited.

\section{ABSTRACT}

Single-component adjuvant is prone to eliciting a specific type of Th1 or Th2 response. So, the development of combinatorial adjuvants inducing a robust mixed Th1/Th2 response is a promising vaccination strategy against cancer. Here, we describe a novel combination of aluminum salts (alum), CpG oligodeoxynucleotide (CpG) and innate defense regulator peptide HH2 for improving anti-tumor immune responses. The CpG-HH2 complex significantly enhanced the production of IFN- $\mathrm{Y}$, TNF-a and IL-1 $\beta$, promoted the uptake of antigen and strengthened the activation of p38, Erk1/2 and NF-KB in vitro, compared to CpG or HH2 alone. Immunization with NYESO-1 antigen plus alum-CpG-HH2 combinatorial adjuvant effectively inhibited tumor growth and reduced tumor burden in prophylactic and therapeutic tumor models and even in passive serum or cellular therapy. In addition, co-administration of NY-ESO-1 with alum-CpG-HH2 combinatorial adjuvant markedly activated NK cell cytotoxicity, induced antibody-dependent cellular cytotoxicity (ADCC), dramatically elicited cytotoxic T lymphocytes (CTLs) response, and increased infiltrating lymphocytes in tumors. Moreover, in vivo depletion of $\mathrm{CD8}^{+} \mathrm{T}$ cells completely and depletion of NK cells partially blocked the anti-tumor activity of NY-ESO-1-alum-CpG-HH2 immunization. Overall, our results demonstrate a novel adjuvant combination for cancer vaccine with efficient immunomodulation by stimulating innate immunity and mediating adaptive immunity.

\section{INTRODUCTION}

Among the enormous approaches for cancer immunotherapy, cancer vaccines are strongly encouraged and highly advanced for its potential benefit in clinic [1]. However, several clinical trials have revealed that tumor-associated antigens in cancer vaccines share weak immunogenicity or poor ability to induce effective cytotoxic T cells (CTLs) and anti-tumor immune responses [2]. Thus, there is still a great need of adjuvants in cancer vaccines for eliciting an efficient and long-lasting anti-tumor immunity [3]. Adjuvants possessing both immunomodulatory effect and enhanced delivery capabilities are essential features for vaccines to generate adequate humoral and cellular immune responses [4]. Addition of adjuvants to certain vaccines enhances the magnitude and durability of antigen-specific immune responses [5]. Yet, a single adjuvant often results in either no response or weak anti-tumor activity. Therefore, development of multiple or combinatorial adjuvants that can induce a broader humoral immune response and desired 
CTLs is a promising approach for design of effective cancer vaccines $[6,7]$.

Recently, some vaccines incorporating combinatorial adjuvants have been well studied in pre-clinical or clinical settings. Forexample,AS04adjuvantcombination(alum+MPL) is employed in two licensed HPV vaccines, Cervarix and Gardasil, to induce higher titers of antibodies [8]. Alum, the unique adjuvant approved by the U. S. Food and Drug Administration (FDA), can sharply augment antigen persistency, antigen uptake and local immunostimulatory response [9]. Recent studies have gradually revealed that alum activates the NALP3 inflammasome followed by the release of IL-1 $\beta$, IL-18, IL-33, and induces a Th2-biased immune response $[10,11]$. However, poor Th1-type immune response induced by alum makes it inappropriate as a single component in cancer vaccines.

Innate defense regulator peptides (IDRs), synthetic mimics of host defense peptides, have weak antimicrobial activity, but have preferable ability to modulate the immune response [12]. HH2 (VQLRIRVAVIRA-NH2) is one of such IDRs, which has recently been shown to induce the production of MCP-1 [13], modulate human neutrophil functions [14] and suppress bacterial infection via enhancing chemokine induction and cell recruitment [15]. Remarkably, $\mathrm{HH} 2$ has demonstrated a promising function as a component of vaccine adjuvants. Our previous studies have shown that $\mathrm{HH} 2$ improves the adjuvant activity of alum-polysaccharide complex [16]. Alumpolysaccharide-HH2 combinational adjuvant effectively stimulates protective cellular immune responses and anti-tumor immunity [16]. Furthermore, in response to the combination of alum and $\mathrm{HH} 2$, the Th1-type immune response is improved, while the Th2-type immunity persists predominantly [16].

CpG-ODN, triggering a Th1-type immune response via interaction with Toll-like receptor 9 (TLR9), has gained considerable interests as a candidate immunomodulator for therapeutic application against tumors [17-20]. The adjuvant combination composed of $\mathrm{CpG}$ and other adjuvants has been applied to activate $\mathrm{CD}^{+} \mathrm{T}$ cells in clinical trials of melanoma vaccines [21, 22]. Recently, the enhanced adjuvant activities of CpG$\mathrm{HH} 2$ complex have been reported. $\mathrm{CpG}$ synergizes with $\mathrm{HH} 2$ to activate innate immune responses [23, 24] and link innate and adaptive immunity [25]. Our previous work has shown that $\mathrm{HH} 2$ changes the type of immune responses induced by alum- $\mathrm{CpG}$ combination and reduces the side effect induced by $\mathrm{CpG}$. Moreover, compared with alum alone, alum-CpG-HH2 combinatorial adjuvant results in excellent humoral immunity, enhances $\mathrm{T}$ cell proliferative response and especially balances Th1/Th2 immune response [26]. Based on the above findings, we hypothesized that the combination of alum, $\mathrm{CpG}$ and $\mathrm{HH} 2$ could avoid moderate efficacy or side effect caused by a single adjuvant and induce a mixed Th1/Th2 response.

In this report, we present evidence showing the activity of alum-CpG-HH2 combinatorial adjuvant in cancer vaccine. Immunization with NY-ESO-1 and
alum-CpG-HH2 combinational adjuvant significantly enhanced Th2-type immune response and especially induced desired Th1-type immune response. Importantly, the tumorigenesis and growth of tumors in mice were dramatically suppressed by co-administration of NYESO-1 with alum-CpG-HH2 combinatorial adjuvant.

\section{RESULTS}

\section{The CpG-HH2 complex induces secretion of cytokines, promotes the uptake of antigen, and enhances the activation of $\mathrm{p38}$, Erk1/2 and NF- $\kappa \mathrm{B}$ in vitro}

To assess the immunostimulatory effect of the CpG$\mathrm{HH} 2$ complex, first we analyzed the expression levels of three key immune regulators: IFN- $\gamma$, TNF- $\alpha$ and IL- $1 \beta$, in PBMCs. For this, human PBMCs were stimulated with $\mathrm{CpG}, \mathrm{HH} 2$ or CpG-HH2 complex for $24 \mathrm{~h}$, followed by ELISA analysis. A synergistic effect was concluded if the expression levels of the cytokines induced by $\mathrm{CpG}-\mathrm{HH} 2$ complex were at least 2-fold higher compared with the summed cytokines released by $\mathrm{CpG}$ alone or $\mathrm{HH} 2$ alone. Of note, CpG-HH2 complex resulted in a higher level of IFN- $\gamma(211.1 \pm 18.7 \mathrm{pg} / \mathrm{ml})$ and showed a synergistic effect $(\mathrm{CI}=2.3 \pm 0.4)$. IL-1 $\beta(7,821.5 \pm 1,429.1 \mathrm{pg} / \mathrm{ml})$ and TNF- $\alpha(3,766.5 \pm 389.6 \mathrm{pg} / \mathrm{ml})$ were significantly increased by $\mathrm{CpG}-\mathrm{HH} 2$ complex, compared with $\mathrm{CpG}$ alone or $\mathrm{HH} 2$ alone, but did not show a synergistic effect $(\mathrm{CI}=1.8$ for IL-1 $\beta ; \mathrm{CI}=1.2$ for $\mathrm{TNF}-\alpha)$ (Figure $1 \mathrm{~A})$. The results suggest that $\mathrm{CpG}-\mathrm{HH} 2$ complex has better immunostimulatory effect than $\mathrm{CpG}$ or $\mathrm{HH} 2$.

To investigate whether $\mathrm{CpG}-\mathrm{HH} 2$ complex adjuvant had an effect on the function of DCs, antigen uptake was examined. To this end, BMDCs were incubated with Alexa Fluor 488-conjugated native NY-ESO-1 alone or protein adjuvant complex (NY-ESO-1-CpG, NY-ESO-1-HH2 or NYESO-1-CpG-HH2) for $3 \mathrm{~h}$, followed by DAPI staining and confocal laser microscopy. By semi-quantification with ImageJ software, the mean fluorescence intensities of all groups were: 14,544.5 for NY-ESO-1 alone; 56,348 for NY-ESO-1 plus CpG; 18,394.4 for NY-ESO-1 plus HH2; 210,011.5 for three component complex NY-ESO-1-CpG-HH2 (Figure 1B). As expected, the mean fluorescence intensity value of NY-ESO1-CpG-HH2 treatment was the highest in all the groups and displayed a synergistic effect $(\mathrm{CI}=2.8)$.

To identify the signaling pathways activated by CpG-HH2 complex, the phosphorylation of NF- $\mathrm{KB}$ (p65) and p38 and Erk1/2 was examined using Western blotting. As shown in Figure 1C, CpG-HH2 complex was found to considerably induce the phosphorylation of p65 in BMDCs following stimulation for $45 \mathrm{~min}$. Erk1/2 and p38 were also remarkably phosphorylated when BMDCs were incubated with $\mathrm{CpG}-\mathrm{HH} 2$ complex for $30 \mathrm{~min}$. These results suggest that $\mathrm{CpG}-\mathrm{HH} 2$ complex has desired properties to be a promising adjuvant. 


\section{Alum-CpG-HH2-NY vaccine effectively suppresses tumor growth in melanoma models}

Next, we tested the anti-tumor effect of the alumCpG-HH2 combinational adjuvant in mouse melanoma models. In the prophylactic model (Figure 2A), B16bearing mice treated with PBS (control) displayed rapid tumor growth, with a high tumor volume of 2,270 $\mathrm{mm}^{3}$ on day 22 after tumor induction. Vaccination with alum-NY, alum-CpG-NY or alum-HH2-NY had some inhibitory effects on B16-melanoma growth, but showed no significant difference with PBS treatment. Interestingly, vaccination with alum-CpG-HH2-NY significantly blocked the tumor growth, having an average tumor volume of $132 \mathrm{~mm}^{3}$ on day 22 ( $p<0.05$ versus PBS). Moreover, no significant body weight changes or obvious pathological changes of the heart, liver, spleen, lung and kidney were observed in mice treated with any of the vaccine formulations (Supplementary Figure 1).

In the therapeutic model (Figure 2B), mice bearing NY-ESO- $1^{+}$B16 cells were employed. The tumor growth was progressive in a single treatment with PBS or alum-NY (mean volume, 2,431 $\mathrm{mm}^{3}$ and $2,153 \mathrm{~mm}^{3}$, respectively) and slightly attenuated in the treatment with alum-CpG-NY or alum-HH2-NY (mean volume, 1,413 $\mathrm{mm}^{3}$ and $1,434 \mathrm{~mm}^{3}$, respectively). In contrast, vaccination with alum-CpG-HH2-NY drastically blocked the tumor growth (mean volume, $375 \mathrm{~mm}^{3}$ ). Similar results were observed in the Hepa 1-6 hepatoma model (Supplemental Figure 2).

To investigate whether alum-CpG-HH2-NY could stimulate anti-tumor immunity in an adoptive cellular or serum therapy model, we transferred the splenocytes or serum from the different vaccinated $\mathrm{C} 57 \mathrm{BL} / 6$ mice to recipient C57BL/6 mice bearing NY-ESO- ${ }^{+}$B16 cells, using the protocols shown in Figures $2 \mathrm{C}$ and 2D. Tumors grew progressively in PBS group, and there was moderate inhibitory effect on tumor growth in alum-NY, alum-HH2NY or alum-CpG-NY groups. In contrast, tumor growth in alum-CpG-HH2-NY group was markedly inhibited.

To further evaluate the effect of passive serum therapy on human A375-mln1.luc tumor model, A375-
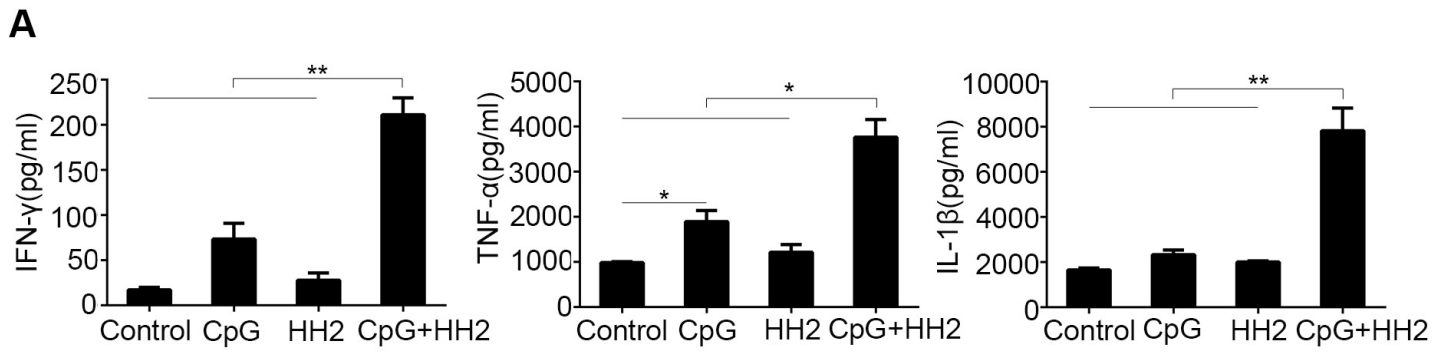
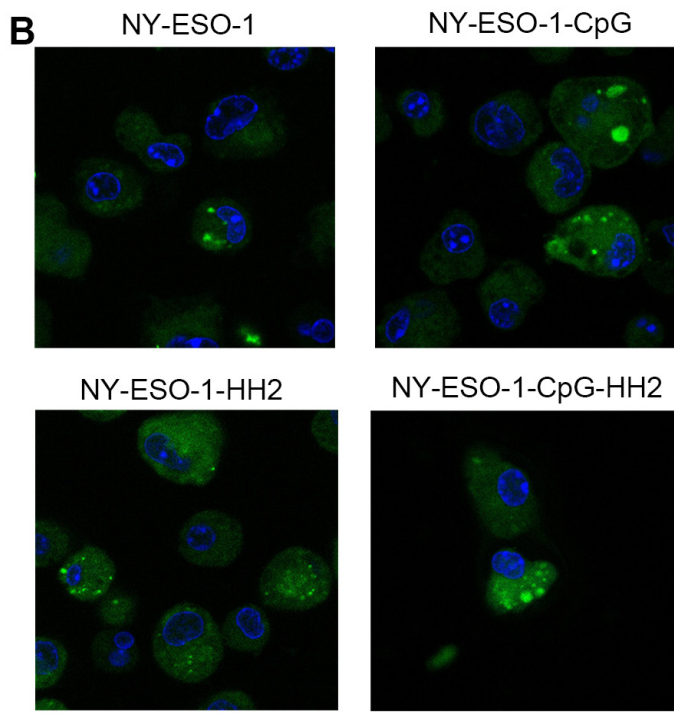
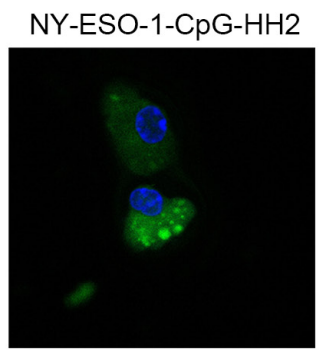

C
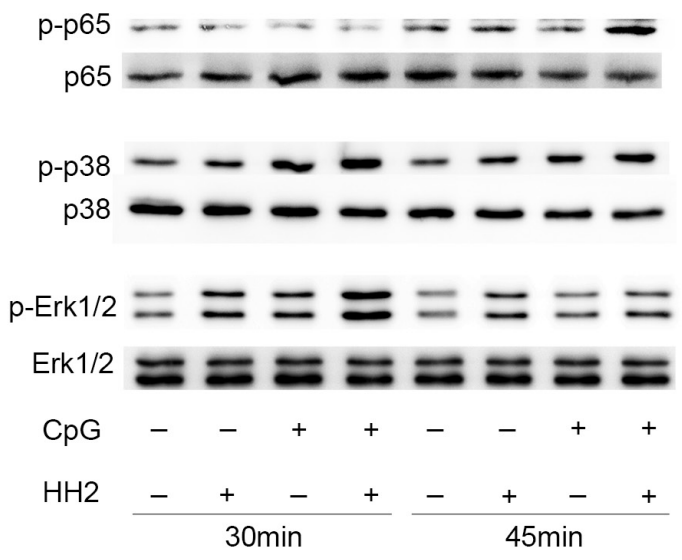

Figure 1: The effects of CpG-HH2 complex in vitro. (A) Human PBMCs $\left(5 \times 10^{5}\right)$ were stimulated with $\mathrm{CpG}, \mathrm{HH} 2$ or $\mathrm{CpG}-\mathrm{HH} 2$ adjuvant complex for $24 \mathrm{~h}$. Then the supernatants were collected and used for cytokines detection by ELISA. Error bars represent mean + SEM. ${ }^{*} p<0.05, * * p<0.01$. (B) BMDCs were incubated with Alexa Fluor 488-conjugated native NY-ESO-1 (green) alone or protein adjuvant complex for $3 \mathrm{~h}$. Cells were subsequently fixed, stained with DAPI (blue) and detected by confocal laser microscopy. (C) Western blot analysis of p-p65, p-p38, and p-Erk1/2 expression. 
bearing nude mice were administered with serum from vaccines-treated or naïve C57BL/6. A significant delay in tumor growth was observed in the alum-CpG-HH2NY-treated mice compared to other groups (Figure 2E). Taken together, these results demonstrate that NY-ESO-1 vaccine with alum-CpG-HH2 combinatorial adjuvant has much more potent anti-tumor activity in vivo than that with alum, alum-CpG or alum-HH2.

\section{Antigen-specific humoral immune response is strongly stimulated by alum-CpG-HH2-NY vaccine}

The antigen-specific antibody triggered by the various vaccines was assessed one week after the third immunization in prophylaxis against B16 melanoma. We found that alum-CpG-NY vaccine elevated the titers of

B

A
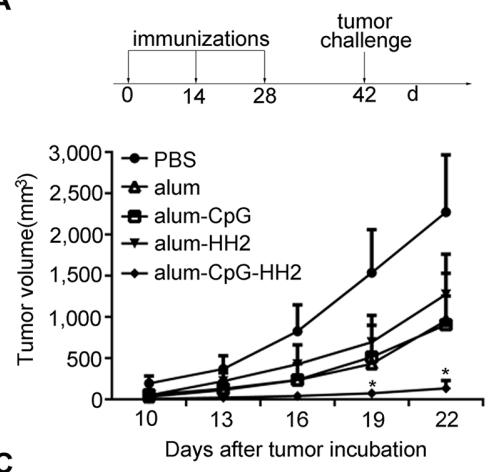

C
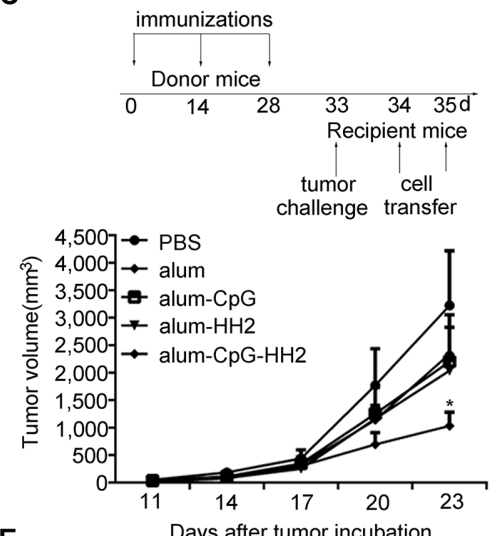

E

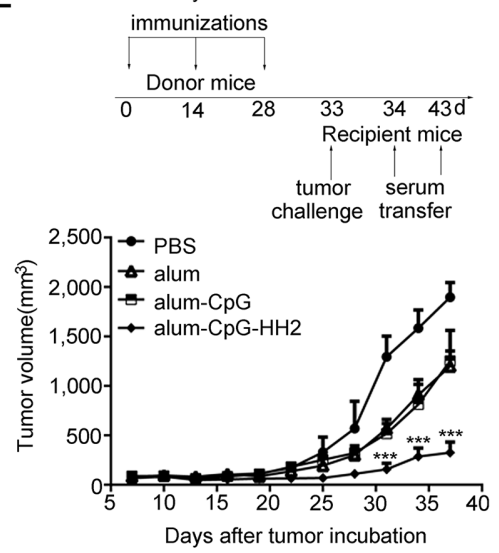

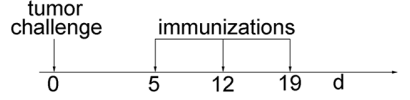
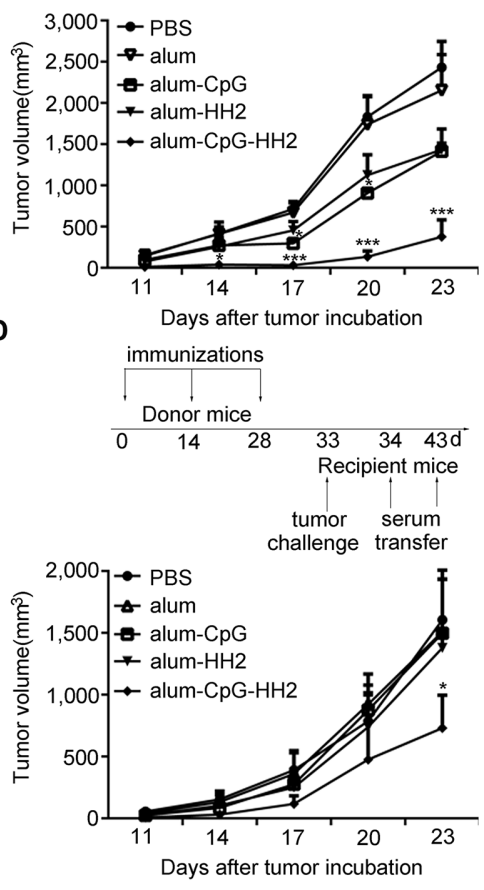

Figure 2: Enhanced anti-tumor immunity by alum-CpG-HH2-NY vaccine in melanoma models. (A) A comparison of the tumor growth in B16-bearing mice was performed in the prophylactic model (10 mice/group). Error bars represent mean $+\mathrm{SEM}$. ${ }^{*} p<0.05$. (B) In a therapeutic model, mice were inoculated with $2 \times 10^{5}$ NY-ESO- $1^{+}$B16 cells and treated with indicated vaccines on days 5 , 12 and 19 (6 mice/group). Error bars represent mean + SEM. $* * * p<0.001$. (C and D) The adaptive transfer experiments were conducted. Donor animals were treated with indicated vaccines on days 0,14 , and 28 . Then the serum or splenocytes were prepared one week after the third immunization. Recipient mice (6 per group) were challenged with $2 \times 10^{5} \mathrm{NY}-\mathrm{ESO}-1^{+} \mathrm{B} 16$ cells on day 33 and i.v injected with $2 \times 10^{7}$ splenocytes from donor animals on days 34 and 35 (C) or $0.1 \mathrm{ml}$ of the sera from donor animals on days 34 to 43 (D). Error bars represent mean + SEM. ${ }^{*} p<0.05$. (E) Tumor volume curves in female nude mice-bearing human A375 cells after injection with the sera from donor animals. Error bars represent mean + SEM. $* * * p<0.001$. 
IgG and IgG2a slightly but not significantly, compared to alum-NY or alum-HH2-NY vaccines. On the contrary, mice receiving alum-CpG-HH2-NY vaccine had significantly higher IgG and IgG2a titers than those receiving alumNY vaccine $(p<0$. 05) (Figures 3A-3C). Moreover, alum-CpG-HH2-NY vaccine induced a considerable higher IgG1 titers than other three groups $(p<0$. 05) (Figure 3B). In addition, antibody binding to NY-ESO$1^{+} \mathrm{B} 16$ melanoma cells was detected by flow cytometry. As expected, the largest amount of antibody was observed in the alum-CpG-HH2-NY group at serum dilution ratio 1:400 (Figure 3D). Moreover, alum-CpG-HH2-NY group displayed an increasing serum binding positive index of NY-ESO- $1^{+} \mathrm{B} 16$ with a reduced serum dilution ratio (Figure 3E), suggesting that the combination between NY-ESO- $1^{+}$B16 cells and antibody had high specificity. To analyze the ex vivo ADCC activity of anti-NY-ESO-1 antibody, NY-ESO- $1^{+}$B16 melanoma cells were exposed to serum from different groups followed by the incubation with splenocytes from PBS or vaccines-treated groups.

A

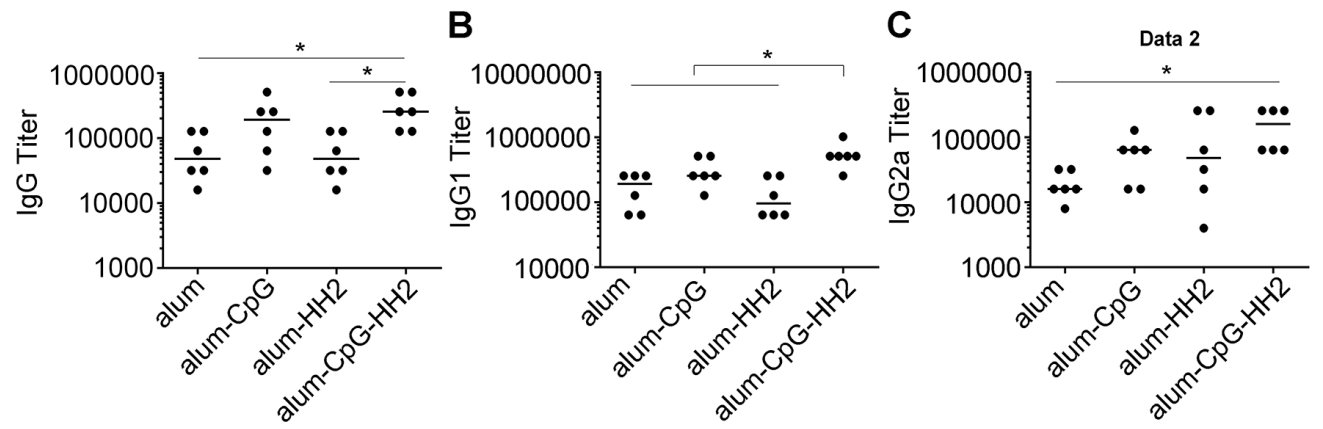

D

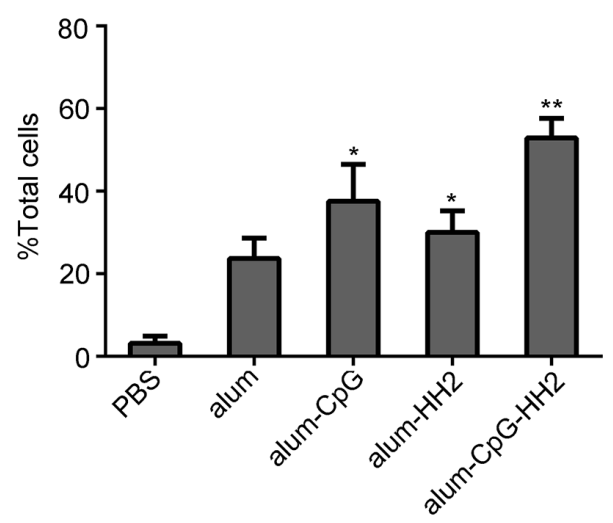

E

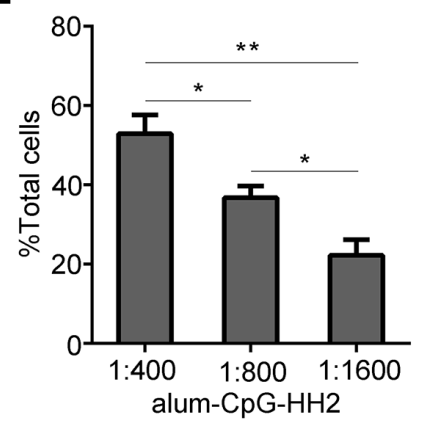

F

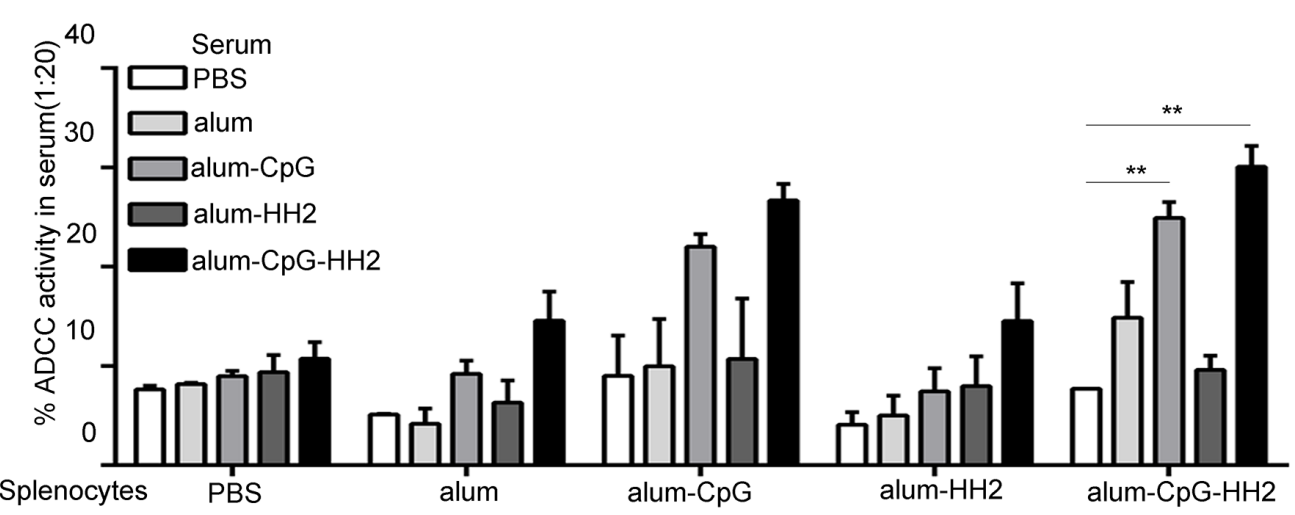

Figure 3: NY-ESO-1-specific antibody response induced by alum-CpG-HH2-NY vaccine. (A-C) ELISA was used to detect the titers of total $\mathrm{IgG}, \mathrm{IgG} 1$ and $\mathrm{IgG} 2 \mathrm{a}$ of anti-NY-ESO-1 antibodies in the treated groups, respectively. Error bars represent median. (D) The NY-ESO-1-specific IgG antibodies binding NY-ESO- $1^{+}$B16 melanoma cells were determined by FACS analysis $(\mathrm{n}=3$ mice). Error bars represent mean + SEM. ${ }^{*} p<0.05, * * p<0.01$. (E) Specificity of anti-NY-ESO-1 antibodies from the serum against NY-ESO-1 was detected by FACS analysis $\left(\mathrm{n}=3\right.$ mice). Error bars represent mean $+\mathrm{SEM}$. ${ }^{*} p<0.05, * * p<0.01$. (F) Antibody-dependent cellular cytotoxicity was determined using the ${ }^{51} \mathrm{Cr}$-release assay $(\mathrm{n}=3$ mice $)$. Error bars represent mean $+\mathrm{SEM} .{ }^{* *} p<0.01$. 
As shown in Figure 3F, the highest ADCC activity ex vivo occurred when both serum and splenocytes came from alum-CpG-HH2-NY group. The results suggest that alumCpG-HH2-NY vaccine strongly stimulates antigen-specific humoral immune response.

\section{Alum-CpG-HH2-NY vaccine induces a potent NK cell cytotoxicity and CTLs activity}

Stimulated and activated NK cells occur predominantly during the early phases of the immune
A

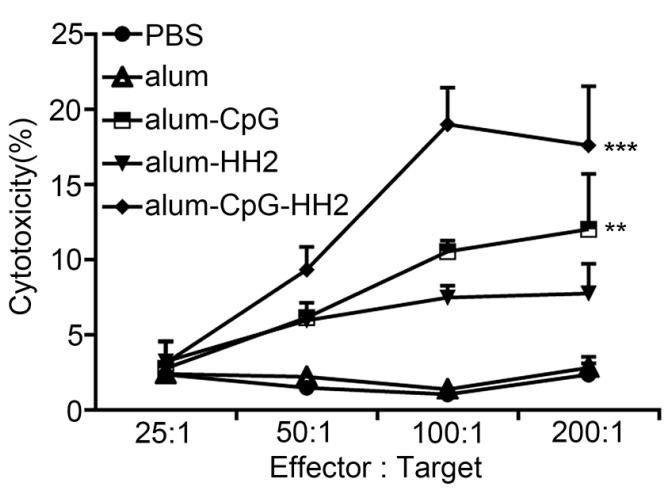

C

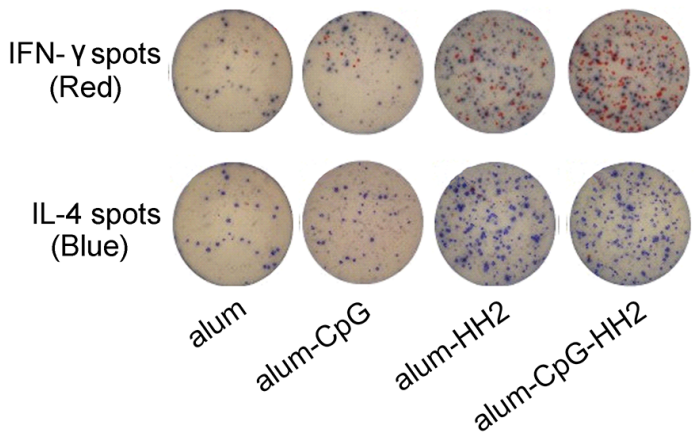

B

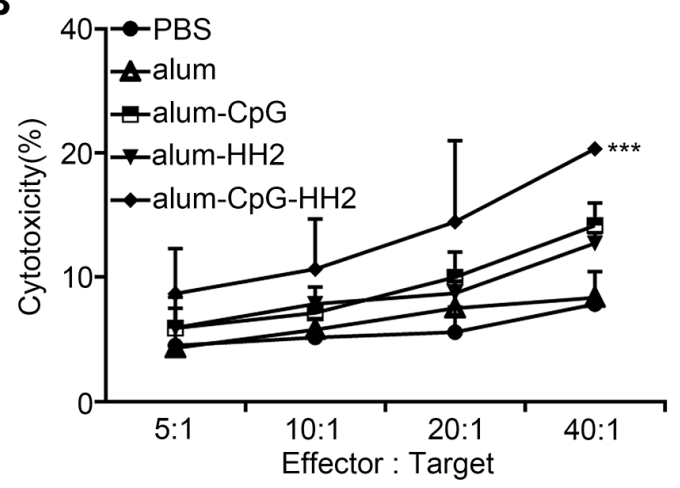

D

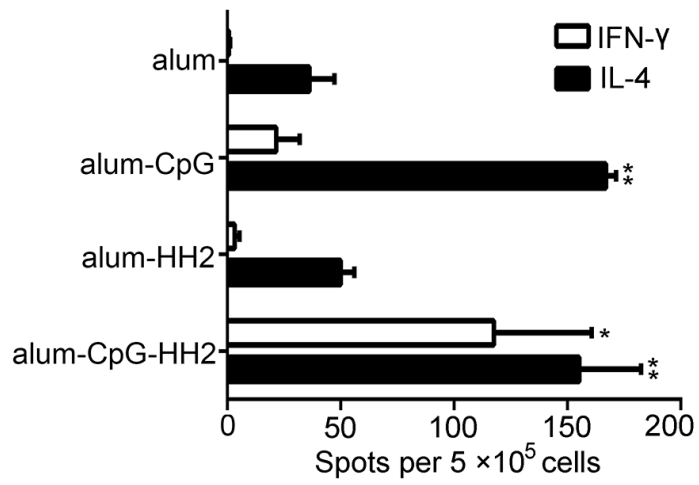

E
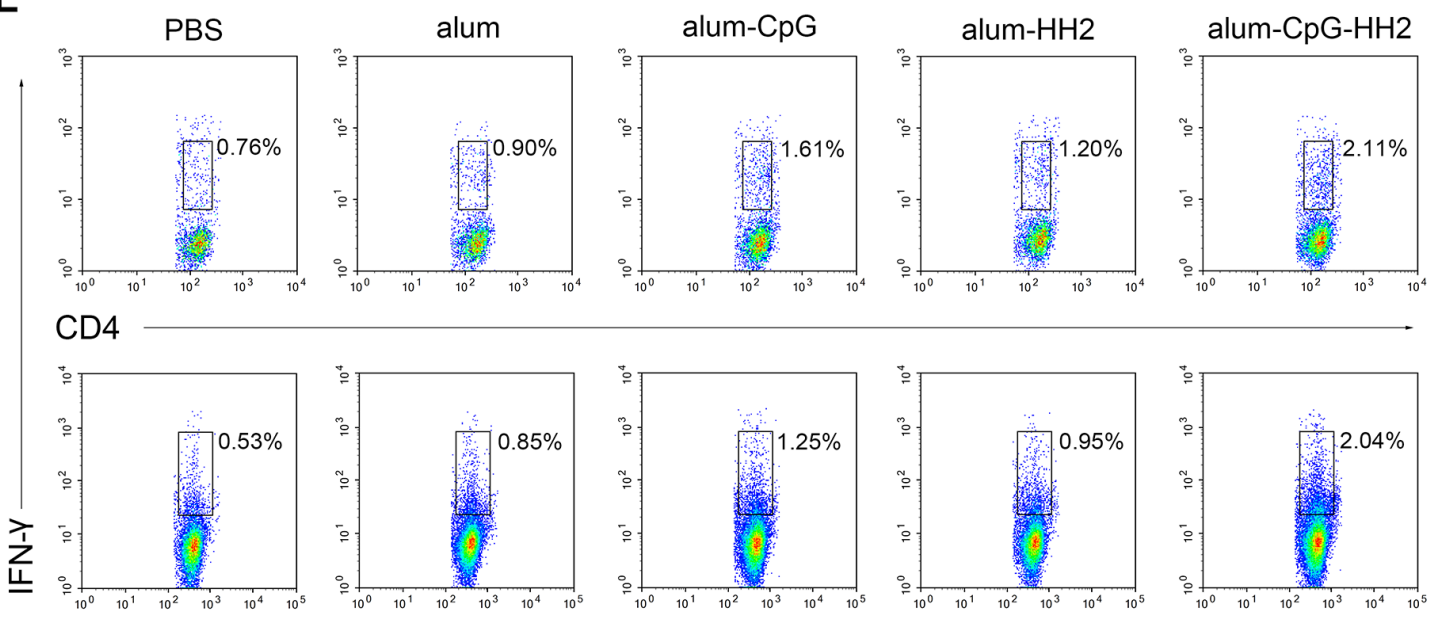

CD8

Figure 4: NK cytolytic activity and specific cellular response elicited by alum-CpG-HH2-NY vaccine. (A) The 4-h NK assay against YAC-1 targets was determined at various effector:target ratios. Error bars represent mean + SEM. $* * p<0.01, * * * p<0.001$. (B) The cytolytic activity of splenocytes against NY-ESO- $1^{+} \mathrm{B} 16$ cells was measured using a $4 \mathrm{~h}{ }^{51} \mathrm{Cr}$-release assay at various E:T ratios. Error bars represent mean + SEM. ${ }^{* *} p<0.001$. (C) The representative graphs of spot-forming cells for IFN- $\gamma$ and IL-4 at one week postimmunization in the ELISpot assay. (D) The average number of IL-4/IFN- $\gamma$ secreting splenocytes was calculated ( $\mathrm{n}=3$, three independent experiments). Error bars represent mean + SEM. ${ }^{*} p<0.05, * * p<0.01$. (E) T cell analysis in splenocytes after vaccination. Intracellular staining of IFN- $\gamma$ in $\mathrm{CD}^{+}$and $\mathrm{CD} 8^{+} \mathrm{T}$ cells was analyzed by FACS. 
response, playing a crucial role in anti-tumor immunity. Next, the NK cell activity from each group at $48 \mathrm{~h}$ after the first immunization was compared at different effector : target ratio $(25: 1,50: 1,100: 1$, and 200:1). As shown in Figure 4A, no significant NK cell activity against YAC-1 cells was found in animals vaccinated with PBS, alum$\mathrm{NY}$, or alum-HH2-NY at different E:T ratios, while high NK cytotoxicity was detected from alum-CpG-NY group, compared with the above-mentioned groups $(p<0.05)$. The NK cytolytic activity was even higher in alum-CpGHH2-NY group than in the alum-CpG group ( $p<0.001)$, and a maximal cytotoxicity was acquired using 100:1 ratio. The results support that alum-CpG-HH2-NY vaccine induces a potent NK cell cytotoxicity.
To assess the CTLs activity induced by alum-CpG$\mathrm{HH} 2-\mathrm{NY}$ vaccine, splenocytes were activated and employed as effectors to recognize NY-ESO-1 ${ }^{+} \mathrm{B} 16$ melanoma cells. PBS, alum-NY, alum-CpG-NY and alum-HH2-NY induced no or moderate CTLs activity. In contrast, alum-CpG-HH2NY vaccine induced remarkable tumor antigen-specific cytotoxic activity $(p<0.001)$ (Figure 4B). In addition, the number of spot-forming cells (SFCs) for IFN- $\gamma$ and IL-4 was evaluated by ELISpot. As shown in Figures $4 \mathrm{C}$ and $4 \mathrm{D}$, the number of IL-4 SFCs in alum-CpG-NY group was significantly higher than that in alum-NY or alum-HH2NY group. Addition of $\mathrm{HH} 2$ to alum-CpG-NY vaccine did not further increase the number of IL-4 SFCs, compared to alum-CpG-NY. Interestingly, there was a significant

A

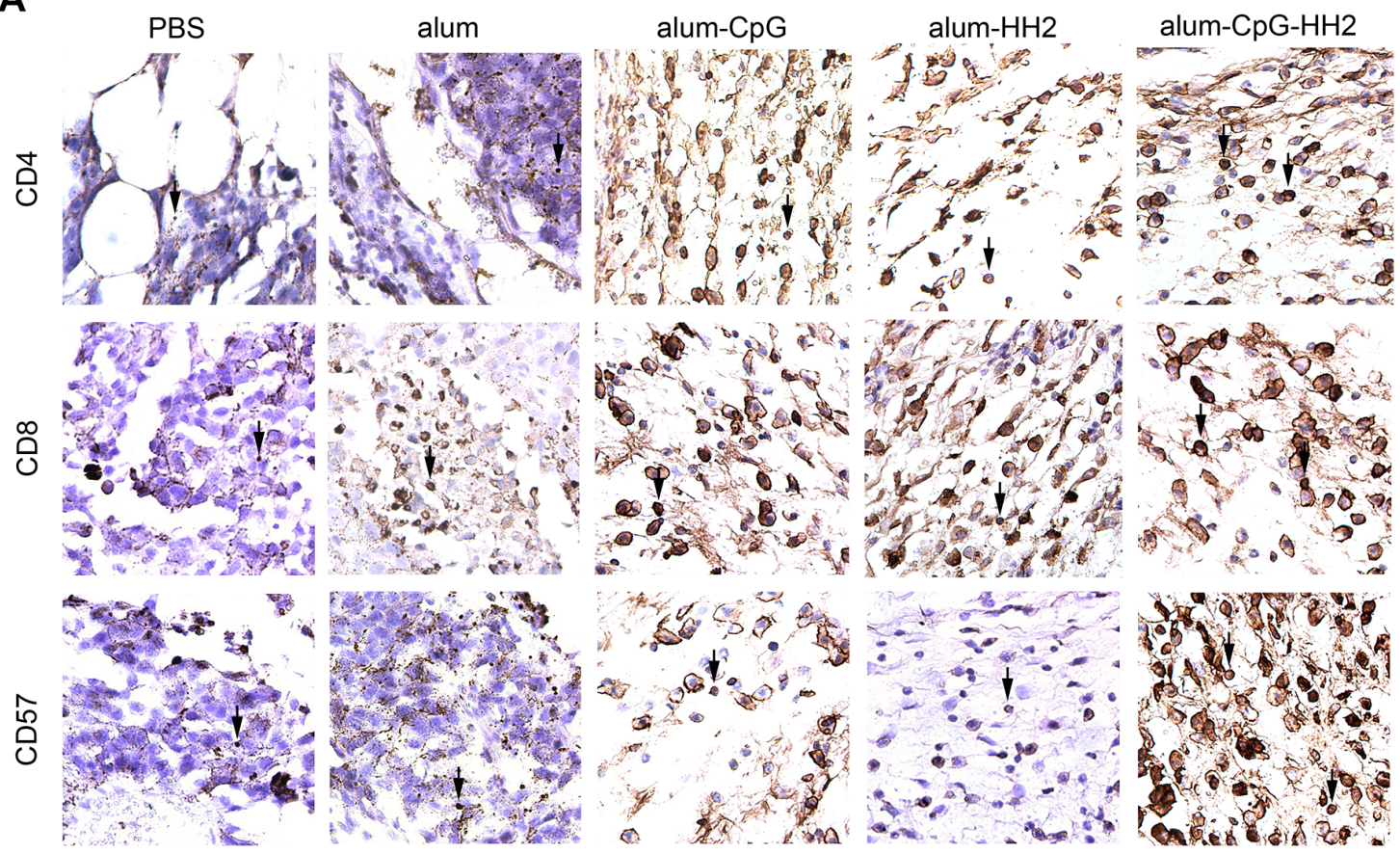

B

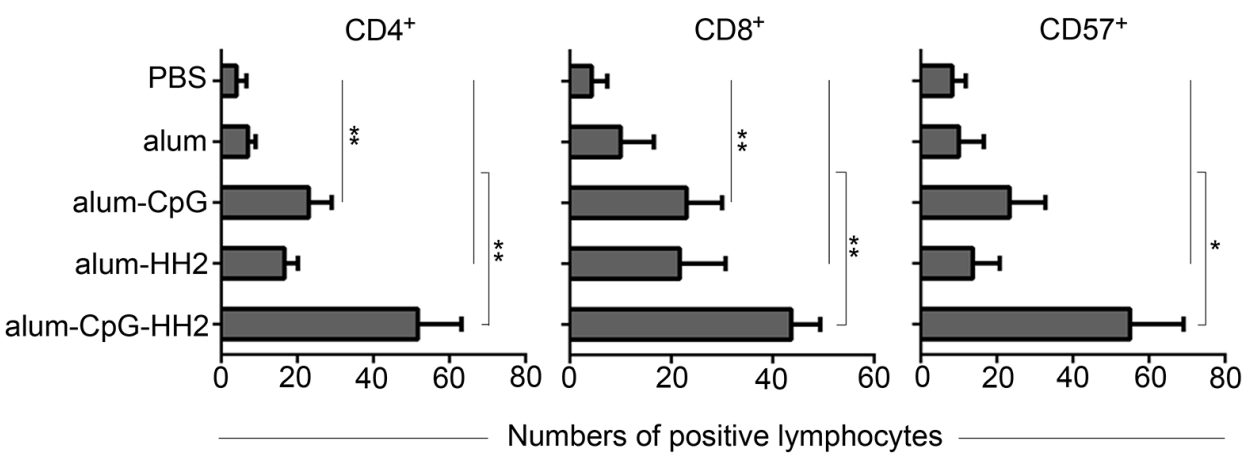

Figure 5: Lymphocyte infiltration in mice melanoma model by immunohistochemistry analyses. (A) A part of the whole graph from IHC staining for lymphocyte infiltration in each group (box-marked graphs from Supplementary Figure 3). Serial sections of tumor tissue were stained with anti-CD4, anti-CD8 and anti-CD57 mAbs at $4{ }^{\circ} \mathrm{C}$ overnight. Afterwards, sections were exposed to antimouse biotinylated antibody and streptavidin-biotinylated orseradish peroxidase complex. (B) The semi-quantification of CD4 ${ }^{+}, \mathrm{CD} 8^{+}$and $\mathrm{CD} 57^{+}$lymphocytes in the tumor tissues was performed. The arrows indicate the positive lymphocytes. Error bars represent mean $+\mathrm{SEM}$. $* p<0.05, * * p<0.01$ 
elevation of IFN- $\gamma$ SFCs in alum-CpG-HH2-NY group compared with alum-CpG-NY group $(p<0.05)$. These observations were further confirmed by analyzing the levels of IFN- $\gamma$-secreting $\mathrm{CD}^{+} / \mathrm{CD}^{+} \mathrm{T}$ cells in each group. Similarly, the proportion of NY-ESO-1 specific IFN- $\gamma$ secreting $\mathrm{CD}^{+} / \mathrm{CD}^{+} \mathrm{T}$ cells was significantly higher in alum-CpG-HH2-NY group than in other groups (Figure $4 \mathrm{E})$. Collectively, the results indicate that alum-CpG-HH2NY vaccine induces a potent CTLs activity.

\section{Alum-CpG-HH2-NY vaccine increases lymphocytes infiltration into tumors}

Infiltration of $\mathrm{CD}^{+}, \mathrm{CD}^{+}$, and $\mathrm{CD} 57^{+}$lymphocytes in tumors was investigated by IHC analyses. As shown in Figures $5 \mathrm{~A}$ and $5 \mathrm{~B}$, the proportions of $\mathrm{CD}^{+}, \mathrm{CD}^{+}$, and $\mathrm{CD} 57^{+}$lymphocytes were small in both PBS and alumNY groups but slightly increased in alum-HH2-NY group. $\mathrm{CD}^{+}, \mathrm{CD}^{+}$, and $\mathrm{CD} 57^{+}$lymphocytes were abundant in alum-CpG-NY group. By statistical analysis, we found that the proportions of $\mathrm{CD}^{+}$and $\mathrm{CD} 8^{+}$lymphocytes were significantly increased in alum-CpG-NY group compared to PBS group. Importantly, the proportions of $\mathrm{CD}^{+}, \mathrm{CD}^{+}$, and $\mathrm{CD} 57^{+}$lymphocytes were very significantly higher in tumors from the alum-CpG-HH2-NY group compared to almost all other groups (Figure 5).

\section{The protection of alum-CpG-HH2-NY- immunized mice is impaired in the absence of NK cells and $\mathrm{CD8}^{+} \mathrm{T}$ cells}

Our above findings that alum-CpG-HH2-NY vaccine was able to enhance humoral immunity, induce NK cell activity and activate CTLs activity suggest that $\mathrm{CD}^{+} \mathrm{T}, \mathrm{NK}$ and $\mathrm{CD}^{+} \mathrm{T}$ cells may play an important role in anti-tumor immunity. Next, we examined the anti-tumor response induced by alum-CpG-HH2-NY vaccine in the absence of $\mathrm{CD}^{+}$and $\mathrm{CD}^{+} \mathrm{T}$ and $\mathrm{NK}$ cells, using the protocol shown in Figure 6A. Treatment with rat IgG2a or IgG2b had no or little impairment of protection elicited by alum-CpG-HH2-NY vaccine (Figure 6B). Depletion of $\mathrm{CD}^{+} \mathrm{T}$ cells entirely abrogated the anti-tumor immunity of alum-CpG-HH2-NY, whereas depletion of $\mathrm{CD}^{+}$ $\mathrm{T}$ cells slightly diminished the anti-tumor immunity and showed no statistical difference relative to $\mathrm{IgG} 2 \mathrm{~b}$ treatment (control) (Figure 6C). Depletion of NK cells significantly attenuated the anti-tumor immunity of alumCpG-HH2-NY (Figure 6D). These results suggest that NK
A

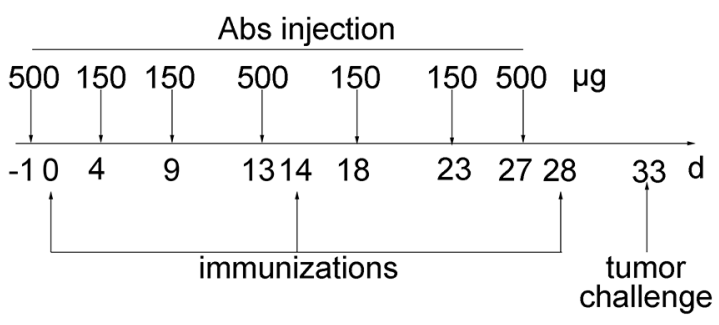

C

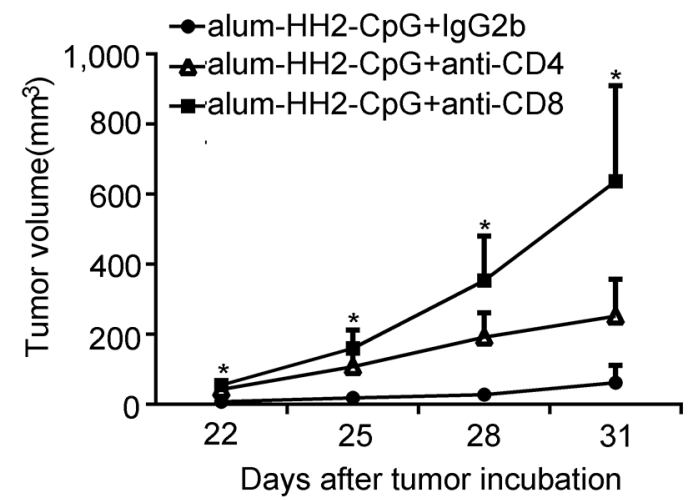

B

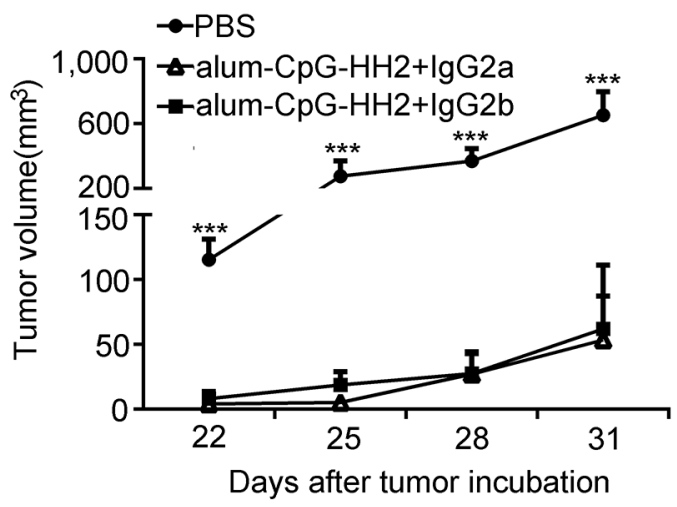

D

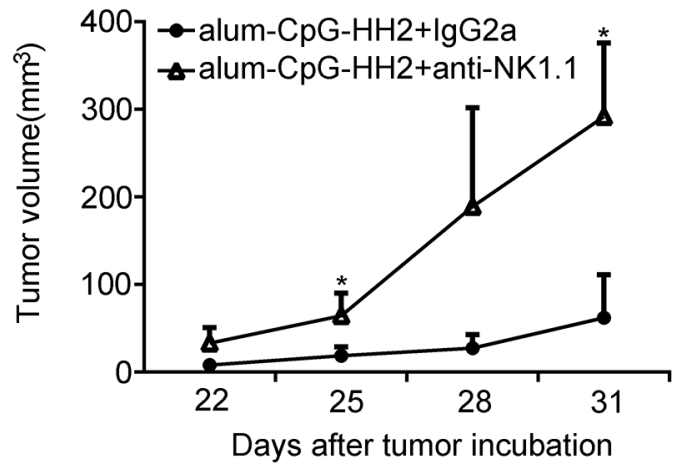

Figure 6: Impaired protection of alum-CpG-HH2-NY-immunized mice by depletion of the immune cell subsets. (A) A representative schedule of immune cell subsets depletion (described in Materials and Methods). (B-D) The curve graphs exhibited the tumor growth of each group ( 6 per group) and the abrogation of the anti-tumor immunity was examined in the absence of CD4 $4^{+} \mathrm{T}$ cells, $\mathrm{NK}^{-}$ cells and $\mathrm{CD}^{+} \mathrm{T}$ cells. Error bars represent mean $+\mathrm{SEM} . * p<0.05, * * * p<0.001$. 
cells and $\mathrm{CD}^{+} \mathrm{T}$ cells play a critical role in anti-tumor activity of alum-CpG-HH2-NY vaccine, while $\mathrm{CD}^{+} \mathrm{T}$ cells may be a potent inducer of humoral immunity and make partial contribution to anti-tumor immunity of alumCpG-HH2-NY.

\section{DISCUSSION}

Despite extensive research and accumulating advances in cancer treatment in recent years, cancer is still the leading cause of death in most countries, indicating that it is urgently needed to develop novel and effective treatments. Cancer immunotherapy is regarded as a promising strategy to combat cancer [27] . On the way to cancer immunotherapy, cancer vaccines containing tumor-associated antigens and adjuvants have made exciting achievements in clinical settings [4]. NYESO-1, a cancer-testis antigen, is expressed in diverse human tumor types, but is not found in normal tissues except for germ cells and trophoblasts [28]. NY-ESO-1 is a prospective tumor antigen for clinical trials because of the high immunogenicity and tissue distribution [29, 30]. In this study, we demonstrated that alum-CpG-HH2 combinatorial adjuvant was able to enhance the anti-tumor activity of NY-ESO-1 vaccine in multiple tumor models.

Results from antigen uptake analysis showed that the $\mathrm{CpG}-\mathrm{HH} 2$ combinatorial adjuvant effectively promoted the uptake of NY-ESO-1 antigen by dendritic cells in vitro. All adjuvants make certain contributions to antigen presentation including antigen uptake by antigenpresenting cells (APC), activation of APC and expression of co-stimulatory molecules in a direct or indirect manner [31]. The functions of dendritic cells described above play a central regulatory role in the initiation of tumor immunity [32]. Moreover, the maturation of DCs by upregulating the expression of surface markers CD80, CD86 and MHCII has been reported in our previous researches [26].

It has been described that $\mathrm{CpG}$ specifically induces the activation of TLR9, resulting in various biological functions, in which the activation of MAPK and NF- $\kappa B$ was required [33, 34]. Cationic antimicrobial peptides, such as LL-37, can also activate Erk1/2, p38 or NF-кB [35]. In this study, the stronger promotion in the activation of NF- $\mathrm{NB}$ and the phosphorylation of Erk1/2 and p38 was observed in the BMDCs stimulated with $\mathrm{CpG}-\mathrm{HH} 2$ combination than single component. Molecular pathways of alum in dendritic cells and macrophages have been described [36] as follows. The binding of alum to cell membrane induces the formulation of lipid raft which activates the ITAM-Syk-PI3K $\delta$ pathway followed by the activation of p38 MAP kinase. Furthermore, the release of dsDNA induced by alum can activate NF- $\kappa$ B. Therefore, we speculate that alum-CpG-HH2 induced strong activation of p38 MAP kinase and NF- $\kappa$ B, which might be associated with its enhanced anti-tumor immunity.
Undoubtedly, the precise molecular mechanism behind the anti-tumor immunity of the combinational adjuvant remains to be further studied.

Natural killer $(\mathrm{NK})$ cells are the primary effector lymphocytes of the innate immune response [37]. Activated NK cells can also induce the production of IFN- $\gamma$, TNF- $\alpha$, and a variety of important cytokines and chemokines [38]. $\mathrm{CpG}$ is a potent stimulator of $\mathrm{NK}$ cells [39]. NK cell cytotoxicity occurs when multiple adjuvants are present. As expected, alum-CpG-NY was effective in activating NK cells compared to PBS, alumNY or alum-HH2-NY. However, interestingly, alum-CpG$\mathrm{HH} 2-\mathrm{NY}$ vaccine was able to induce the highest NK cell killing capacity, among all adjuvants tested in this study. Depletion of NK cells partially attenuated the anti-tumor immunity induced by alum-CpG-HH2-NY vaccine, suggesting that NK cells may be involved in the early phases of generating anti-tumor immunity [40].

In recent years, vaccine adjuvant design inducing Th1 type immune response has been a promising strategy for cancer vaccines [3, 41-43]. The production of IFN- $\gamma$ and TNF- $\alpha$ was examined in this study. Our results revealed that $\mathrm{CpG}$ combined with $\mathrm{HH} 2$ markedly enhanced the expression of IFN- $\gamma$ in PBMCs in vitro and showed a synergistic effect compared to $\mathrm{CpG}$ or $\mathrm{HH} 2$ alone. The up-regulation of TNF- $\alpha$ by $\mathrm{CpG}-$ $\mathrm{HH} 2$ combination was statistically significant but not synergistic. This fact strongly suggests that Th1 type immune response was driven by the enhanced secretion of Th1-type cytokines, which typically activate CTLs, monocytes, NK cells, macrophages to fight tumor [44, 45]. CTLs are critical effector cells in anti-tumor immune responses by specifically recognizing their target cells and secreting cytolytic contents [46]. The strongest stimulation of the CTLs activity of spleen cells was observed in mice treated with alum-CpG-HH2-NY vaccine. Moreover, compared to other four groups, alum-CpG-HH2-NY vaccine induced a highest level of IFN- $\gamma$-secreting $\mathrm{CD}^{+}$ $\mathrm{T}$ cells. Importantly, depletion of $\mathrm{CD}^{+} \mathrm{T}$ cells completely abrogated the anti-tumor immunity of alum-CpG-HH2$\mathrm{NY}$ vaccine, indicating that $\mathrm{CD} 8^{+} \mathrm{T}$ cells is a very crucial fighter against tumor cells.

In this study, we also examined humoral immune response and lymphocyte infiltration in mice treated with various adjuvant combinations in vitro. Mice treated with alum-CpG-HH2-NY vaccine had the highest titers of $\mathrm{IgG}$, which may be related to the significant induction of ADCC against NY-ESO- $1^{+} \mathrm{B} 16$ cells. ADCC activity, one of the critical parameters for vaccine design or efficacy of therapeutic antibodies, is capable of directly triggering apoptosis of target cells $[47,48]$. Depletion of $\mathrm{CD}^{+} \mathrm{T}$ cells weakly attenuated the anti-tumor effect of alumCpG-HH2-NY vaccine, supporting that $\mathrm{CD}^{+} \mathrm{T}$ cells might be a potent inducer of humoral immunity and required for $\mathrm{CD}^{+}$CTL response [49]. In addition, the preponderance of CD4, CD8, and CD57-positive lymphocytes being 
accessing to the tumor cells in the group immunized with alum-CpG-HH2-NY vaccine may also make certain contributions to tumor regression.

These above actions involve enhanced cytokines production, activated NK cell activity and CTL activity, as well as elevated humoral immunity and lymphocyte infiltration, all of which may contribute to the anti-tumor activity of alum-CpG-HH2-NY vaccine. In conclusion, our data demonstrated that alum-CpG-HH2 combination is a safe, effective and promising adjuvant combination, which can effectively trigger innate immunity, modulate humoral immune response and especially stimulate Th1 type immune response to suppress the tumor growth. The alum-CpG-HH2 combinatorial adjuvant lays a foundation for a novel approach for cancer therapy.

\section{MATERIALS AND METHODS}

\section{Mice and cell lines}

Female C57BL/6 (6-8 weeks old) and nude mice (4-6 weeks old) were provided by Huafukang Biological Technology Company (Beijing, China). All mice were maintained under SPF conditions and in accordance with protocols approved by the Ethics Review Committee for Animal Experimentation of Sichuan University. NYESO- $1^{+}$B16-F10 melanoma cells and NY-ESO- $1^{+}$Hepa16 cells stably expressing human NY-ESO-1 were prepared in our lab as described previously [16], and cultured in Dulbecco's modified Eagle's medium (DMEM, Gibco, Grand Island, USA) supplemented with 10\% fetal bovine serum (FBS) (Gibco, Grand Island, USA) and $800 \mu \mathrm{g} / \mathrm{ml}$ of G418 (Sigma-Aldrich, St. Louis, MO, USA).

\section{Mouse models}

Preparations of NY-ESO-1 protein and vaccines are shown in Supplementary Materials. In the prophylactic model, C57BL/6 mice were subcutaneously (s.c.) vaccinated with alum-NY, alum-CpG-NY, alum-HH2NY, or alum-CpG-HH2-NY on days 0,14 , and 28. PBS was used as a control. NY-ESO- $1^{+} \mathrm{B} 16\left(2 \times 10^{5}\right)$ cells were implanted on the back of mice two weeks after the last immunization and tumor volume was measured every three days from tumor onset ( $\sim 3 \mathrm{~mm}$ diameter). Tumor volume was calculated according to the formula: tumor volume $=0.5 \times$ length $(\mathrm{mm}) \times[\text { width }(\mathrm{mm})]^{2}$.

For the therapeutic tumor experiment, C57BL/6 mice were challenged with a s.c. injection of $2 \times 10^{5}$ NY-ESO- $1^{+}$B16 tumor cells. On day 5 after tumor cell injection, the tumor was palpable $\left(>50 \mathrm{~mm}^{3}\right)$. Mice were then randomized into 5 groups and vaccinated once a week for three times (on days 5, 12, and 19).

In the adoptive transfer settings, C57BL/6 mice were treated with the above vaccines for a total of three injections and splenocytes or serum were collected one week after the third immunization. B16-bearing mice were challenged with an intravenous injection of $2 \times 10^{7}$ donor splenocytes twice (once per day) or $0.1 \mathrm{ml}$ serum for 10 consecutive days on the second day of tumor inoculation. Alternatively, nude mice were challenged with $5 \times 10^{6}$ human melanoma A375 cells (ATCC, Rockville, USA) and then subjected to passive serum therapy as described above.

\section{Analysis of NY-ESO-1 antibody titers}

Antigen-specific antibodies in the serum of one week after the third immunization were determined using ELISA. In short, 2-fold diluted serum was analyzed on 96-well plates (Nunclon, Roskilde, Denmark) coated with $0.1 \mu \mathrm{g}$ NY-ESO-1 protein per well. NY-ESO-1-specific antibodies were probed with goat anti-mouse IgG, IgG2a or IgG1 conjugated with horseradish peroxidase (1:3000; ZSGB-BIO, Beijing,China). Finally, plates were read on an ELISA reader at a wavelength of $450 \mathrm{~nm}$.

To determine the specificity of antibodies, serial dilutions of serum $(1: 400,1: 800$, and 1:1600) were incubated with $3 \times 10^{5} \mathrm{NY}$-ESO- $1^{+} \mathrm{B} 16$ cells for $1 \mathrm{~h}$ at $4^{\circ} \mathrm{C}$ after fixation and permeabilization. The cells were then washed in PBS, stained with FITC-conjugated goat antimouse IgG (BD Pharmingen, San Jose, CA) for $30 \mathrm{~min}$ at $4^{\circ} \mathrm{C}$ and analyzed using BD FACS Calibur flow cytometry (BD Pharmingen).

\section{Detection of ADCC, NK and CTLs activities}

In these experiments, YAC- 1 or NY-ESO- $1^{+} \mathrm{B} 16$ cells were labeled with $100 \mu \mathrm{Ci}^{51} \mathrm{Cr}$ and then used as target cells. In ADCC assay, $1 \times 10^{6} \mathrm{NY}-\mathrm{ESO}-1^{+} \mathrm{B} 16$ cells were exposed to a 1:20 diluted serum followed by labelling with ${ }^{51} \mathrm{Cr}$ at $37^{\circ} \mathrm{C}$ for $1 \mathrm{~h}$. After washing, $1 \times 10^{4}{ }^{51} \mathrm{Cr}$-labelled NY-ESO- $1^{+}$B16 cells were co-incubated with $1 \times 10^{6}$ splenocytes of one week after the third immunization at $37^{\circ} \mathrm{C}$ for $4 \mathrm{~h}$. To detect NK activity, splenocytes were collected at $48 \mathrm{~h}$ after the first vaccination and incubated with ${ }^{51} \mathrm{Cr}$-labelled YAC-1 cells at serial effector:target ratios $(25: 1,50: 1,100: 1$, and $200: 1)$ at $37^{\circ} \mathrm{C}$ for $4 \mathrm{~h}$. For CTLs assay, splenocytes were isolated one week after the third immunization, sensitized with $10 \mu \mathrm{g} / \mathrm{ml} \mathrm{NY-ESO-1}$ protein at $37^{\circ} \mathrm{C}$ for $16 \mathrm{~h}$, and incubated with ${ }^{51} \mathrm{Cr}$-labelled NY-ESO- $1^{+} \mathrm{B} 16$ cells at different effector:target ratios $(5: 1,10: 1,20: 1$, and 40:1). Finally, the supernatants were collected and the released radioactivity was measured using a gamma counter (LKB Wallac, Turku, Finland). Percent lysis was determined according to this formula: (test lysis - spontaneous lysis) / (maximum lysis spontaneous release) $\times 100$.

\section{ELISpot assay and IFN- $\gamma$ intracellular staining}

Splenocytes isolated from PBS- or vaccinesimmunized mice one week after the last immunization were subjected to ELISpot assay and IFN- $\gamma$ intracellular 
staining. The mouse IFN- $\gamma /$ IL-4 Dual-Color ELISpot kit (R\&D Systems, Minneapolis, USA) was used for ELISpot assay. Briefly, $5 \times 10^{5}$ splenocytes were coincubated with $10 \mu \mathrm{g} / \mathrm{ml} \mathrm{NY-ESO-1}$ in the mouse IFN- $\gamma$ specific monoclonal antibody and IL-4-specific polyclonal antibody pre-coated microplates at $37^{\circ} \mathrm{C}$ for $48 \mathrm{~h}$. Next, an enzyme-linked colorimetric assay was carried out for further detection. The viable cells were quantified using an ELISpot reader system (Beijing Dakewe Biotech Company, Beijing, China).

For IFN- $\gamma$ intracellular staining, splenocytes were stimulated in the presence of $10 \mu \mathrm{g} / \mathrm{ml} \mathrm{NY-ESO}-1$ at $37^{\circ} \mathrm{C}$ for $1 \mathrm{~h}$ and then incubated in Golgi Plug for an additional 6 h. After staining with PerCP-anti-mouse CD4 and PE-antimouse CD8 $\alpha$ (BD Pharmingen), splenocytes were fixed and permeabilized using a Cytofix/Cytoperm Kit (BD Pharmingen) according to manufacturer's instructions. The intracellular IFN- $\gamma$ was detected with FITC-antimouse IFN- $\gamma$ (BD Pharmingen) and analyzed on a BD FACS Calibur flow cytometer.

\section{Immunohistochemistry(IHC)}

IHC was conducted using a standard method as previously described [16].

\section{Cytokines assay}

Human peripheral blood mononuclear cells (PBMCs) were isolated from healthy volunteers. PBMCs $\left(5 \times 10^{5}\right.$ per well $)$ were stimulated with $20 \mu \mathrm{g} \mathrm{CpG}, 40 \mu \mathrm{g}$ $\mathrm{HH} 2$ or $20 \mu \mathrm{g} \mathrm{CpG}$ in combination with $40 \mu \mathrm{g} \mathrm{HH} 2$ for 24 $\mathrm{h}$. The supernatants were collected for detecting the levels of IFN- $\gamma$, TNF- $\alpha$ and IL-1 $\beta$ using Quantikine ${ }^{\circledR}$ Human IFN- $\gamma$, TNF- $\alpha$ and IL- $1 \beta$ ELISA kits (R\&D Systems).

\section{Antigen uptake}

Bone marrow cells were isolated from C57BL/6 mice and cultured in the presence of $10 \mathrm{ng} / \mathrm{ml}$ recombinant murine GM-CSF and IL-4 (10ng/ml; both from PeproTech, Rocky Hill, NJ). Bone marrow-derived dendritic cells (BMDCs) from 5-day-old cultures were gathered for further experiments. CpG $(20 \mu \mathrm{g} / \mathrm{ml}), \mathrm{HH} 2(40 \mu \mathrm{g} / \mathrm{ml})$, or $\mathrm{CpG}-\mathrm{HH} 2$ combination were mixed with Alexa Fluor 488-labeled NY-ESO-1 (10 $\mu \mathrm{g} / \mathrm{ml})$ for complex formation at $37^{\circ} \mathrm{C}$ for $15 \mathrm{~min}$. Then BMDCs $\left(2 \times 10^{5}\right.$ per well $)$ were pulsed with Alexa Fluor 488-labelled NY-ESO-1 or NYESO-1/complex adjuvant formulations for $3 \mathrm{~h}$ at $37^{\circ} \mathrm{C}$. At the end of the incubation, cells were washed, fixed, stained with DAPI (Beyotime, Haimen, China) and examined under a confocal microscope.

\section{Western blotting}

BMDCs were incubated with CpG $(20 \mu \mathrm{g} / \mathrm{ml}), \mathrm{HH} 2$ (40 $\mu \mathrm{g} / \mathrm{ml})$, or CpG-HH2 complex for 30 and $45 \mathrm{~min}$, respectively. Protein extracts were prepared from treatedDCs, separated by $12 \%$ SDS-PAGE and transferred onto polyvinylidene fluoride membranes (Millipore, Billerica, MA). The membranes were blocked with 5\% non-fat milk and probed with rabbit antibodies against p65, phospho-p65, p38, phospho-p38, Erk1/2 and phosphoErk1/2 (1:2000; all from Cell Signaling Technology, Beverly, MA) overnight at $4{ }^{\circ} \mathrm{C}$. Then the membranes were incubated with horseradish peroxidase-conjugated goat anti-rabbit IgG (1:5000; ZSGB-BIO, Beijing, China).

\section{In vivo immune cell subsets depletion}

The depletion of $\mathrm{CD}^{+} \mathrm{T}$ cells, $\mathrm{CD}^{+} \mathrm{T}$ cells and $\mathrm{NK}$ cells in vivo was conducted as described [49]. Animals were treated with alum-CpG-HH2-NY vaccine on days 0,14 , and 28 , and challenged with NY-ESO- $1^{+} \mathrm{B} 16$ cells $\left(2 \times 10^{5}\right.$ cells $)$ one week after the third immunization. Mice were injected i.p. with $500 \mu \mathrm{g}$ of either the antibodies [anti-CD4 (clone GK 1.5, rat IgG2b), anti-CD8 (clone 2.43, rat IgG2b), antiNK1.1 (clone PK136, or rat IgG2a)], or isotype controls (rat $\operatorname{IgG} 2 \mathrm{a}$ or $\operatorname{IgG} 2 \mathrm{~b}$ ) one day prior to each vaccine immunization, and then with $150 \mu \mathrm{g}$ of the antibodies twice (5 days once) until next vaccine immunization. PBS served as a control. The depletion of $\mathrm{CD}^{+} \mathrm{T}$ cells, $\mathrm{CD}^{+} \mathrm{T}$ cells and NK cells was determined by flow cytometry.

\section{Statistical analysis}

All statistical analyses were performed using SPSS 16.0 software (SPSS Benelux, Gorinchem, The Netherlands). Comparisons for multiple groups were performed using one-way analysis of variance (ANOVA) test followed by Tukey's multiple-range testing. Values of $p<0.05$ were considered statistically significant.

\section{Abbreviations}

ADCC: antibody-dependent cellular cytotoxicity; Alum: aluminum salts; APC: antigen-presenting cells; BMDCs: bone marrow-derived dendritic cells; CpG: CpG oligodeoxynucleotide; CTLs: cytotoxic T lymphocytes; IDRs: innate defense regulators; IHC: immunohistochemistry; PBMCs: human peripheral blood mononuclear cells; PBS: phosphate-buffered saline; SFCs: spot-forming cells; TLR9: Toll-like receptor 9.

\section{ACKNOWLEDGMENTS}

The authors thank Prof. Shile Huang, Prof. Xiancheng Chen, Prof. Zhu Yuan and Prof. Hongbo Hu for critical reading of the article.

\section{CONFLICTS OF INTEREST}

The authors declare no potential conflicts of interest. 


\section{GRANT SUPPORT}

This work was supported by the National Natural Science Foundation of China (No.31570927); National Major Scientific and Technological Special Project for "Significant New Drugs Development" (No. 2013ZX09102030); National Major Scientific and Technological Special Project for "Significant New Drugs Development" (No. 2014ZX0901041-002).

\section{REFERENCES}

1. Drake CG, Lipson EJ, Brahmer JR. Breathing new life into immunotherapy: review of melanoma, lung and kidney cancer. Nat Rev Clin Oncol. 2014; 11: 24-37. doi: 10.1038/ nrclinonc.2013.208.

2. Vergati M, Intrivici C, Huen NY, Schlom J, Tsang KY. Strategies for cancer vaccine development. J Biomed Biotechnol. 2010; 2010. doi: 10.1155/2010/596432.

3. Dubensky TW Jr, Reed SG. Adjuvants for cancer vaccines. Semin Immunol. 2010; 22: 155-61. doi: 10.1016/j. smim.2010.04.007.

4. Melero I, Gaudernack G, Gerritsen W, Huber C, Parmiani G, Scholl S, Thatcher N, Wagstaff J, Zielinski C, Faulkner I, Mellstedt H. Therapeutic vaccines for cancer: an overview of clinical trials. Nat Rev Clin Oncol. 2014; 11: 509-24. doi: 10.1038/nrclinonc.2014.111.

5. Reed SG, Orr MT, Fox CB. Key roles of adjuvants in modern vaccines. Nat Med. 2013; 19: 1597-608. doi: 10.1038/nm.3409.

6. Srivastava AK, Yolcu ES, Dinc G, Sharma RK, Shirwan H. SA-4-1BBL/MPL as a novel immune adjuvant platform to combat cancer. Oncoimmunology. 2016; 5: e1064580. doi: 10.1080/2162402X.2015.1064580.

7. Mount A, Koernig S, Silva A, Drane D, Maraskovsky E, Morelli AB. Combination of adjuvants: the future of vaccine design. Expert Rev Vaccines. 2013; 12: 733-46. doi: 10.1586/14760584.2013.811185.

8. Skinner SR, Apter D, De Carvalho N, Harper DM, Konno R, Paavonen J, Romanowski B, Roteli-Martins C, Burlet N, Mihalyi A, Struyf F. Human papillomavirus (HPV)-16/18 AS04-adjuvanted vaccine for the prevention of cervical cancer and HPV-related diseases. Expert Rev Vaccines. 2016; 15: 367-87. doi: 10.1586/14760584.2016.1124763.

9. De Gregorio E, Tritto E, Rappuoli R. Alum adjuvanticity: unraveling a century old mystery. Eur J Immunol. 2008; 38: 2068-71. doi: 10.1002/eji.200838648.

10. Eisenbarth SC, Colegio OR, O'Connor W, Sutterwala FS, Flavell RA. Crucial role for the Nalp3 inflammasome in the immunostimulatory properties of aluminium adjuvants. Nature. 2008; 453: 1122-6. doi: 10.1038/nature06939.

11. Marrack P, McKee AS, Munks MW. Towards an understanding of the adjuvant action of aluminium. Nat Rev Immunol. 2009; 9: 287-93. doi: 10.1038/nri2510.
12. Easton DM, Nijnik A, Mayer ML, Hancock RE. Potential of immunomodulatory host defense peptides as novel anti-infectives. Trends Biotechnol. 2009; 27: 582-90. doi: 10.1016/j.tibtech.2009.07.004.

13. Cao D, Li H, Jiang Z, Xu C, Cheng Q, Yang Z, Cao G, Zhang L. Synthetic innate defence regulator peptide enhances in vivo immunostimulatory effects of CpGODN in newborn piglets. Vaccine. 2010; 28: 6006-13. doi: 10.1016/j.vaccine.2010.06.103.

14. Niyonsaba F, Madera L, Afacan N, Okumura K, Ogawa $\mathrm{H}$, Hancock RE. The innate defense regulator peptides IDR-HH2, IDR-1002, and IDR-1018 modulate human neutrophil functions. J Leukoc Biol. 2013; 94: 159-70. doi: 10.1189/jlb.1012497.

15. Rivas-Santiago B, Castaneda-Delgado JE, Rivas Santiago CE, Waldbrook M, Gonzalez-Curiel I, Leon-Contreras JC, Enciso-Moreno JA, del Villar V, Mendez-Ramos J, Hancock RE, Hernandez-Pando R. Ability of innate defence regulator peptides IDR-1002, IDR-HH2 and IDR-1018 to protect against Mycobacterium tuberculosis infections in animal models. PLoS One. 2013; 8: e59119. doi: 10.1371/journal. pone.0059119.

16. Li M, Shi H, Mu Y, Luo Z, Zhang H, Wan Y, Zhang D, Lu L, Men K, Tian Y, Wu X, Liu X, Pan Y, et al. Effective inhibition of melanoma tumorigenesis and growth via a new complex vaccine based on NY-ESO-1-alumpolysaccharide-HH2. Mol Cancer. 2014; 13: 179. doi: 10.1186/1476-4598-13-179.

17. Veenstra JJ, Gibson HM, Littrup PJ, Reyes JD, Cher ML, Takashima A, Wei WZ. Cryotherapy with concurrent CpG oligonucleotide treatment controls local tumor recurrence and modulates HER2/neu immunity. Cancer Res. 2014; 74 : 5409-20. doi: 10.1158/0008-5472.CAN-14-0501.

18. Chang LS, Leng $\mathrm{CH}$, Yeh $\mathrm{YC}, \mathrm{Wu} \mathrm{CC}$, Chen $\mathrm{HW}$, Huang HM, Liu SJ. Toll-like receptor 9 agonist enhances anti-tumor immunity and inhibits tumor-associated immunosuppressive cells numbers in a mouse cervical cancer model following recombinant lipoprotein therapy. Mol Cancer. 2014; 13: 60. doi: 10.1186/1476-4598-13-60.

19. Xia Y, Gupta GK, Castano AP, Mroz P, Avci P, Hamblin MR. CpG oligodeoxynucleotide as immune adjuvant enhances photodynamic therapy response in murine metastatic breast cancer. J Biophotonics. 2014; 7: 897-905. doi: 10.1002/jbio.201300072.

20. Jordan M, Waxman DJ. CpG-1826 immunotherapy potentiates chemotherapeutic and anti-tumor immune responses to metronomic cyclophosphamide in a preclinical glioma model. Cancer Lett. 2016; 373: 88-96. doi: 10.1016/j.canlet.2015.11.029.

21. Fourcade J, Kudela P, Andrade Filho PA, Janjic B, Land SR, Sander C, Krieg A, Donnenberg A, Shen H, Kirkwood JM, Zarour HM. Immunization with analog peptide in combination with $\mathrm{CpG}$ and montanide expands tumor antigen-specific CD8+ T cells in melanoma patients. J Immunother. 2008; 31: 781-91. doi: 10.1097/CJI.0b013e318183af0b. 
22. Sabbatini P, Tsuji T, Ferran L, Ritter E, Sedrak C, Tuballes K, Jungbluth AA, Ritter G, Aghajanian C, Bell-McGuinn K, Hensley ML, Konner J, Tew W, et al. Phase I trial of overlapping long peptides from a tumor self-antigen and poly-ICLC shows rapid induction of integrated immune response in ovarian cancer patients. Clin Cancer Res. 2012; 18: 6497-508. doi: 10.1158/1078-0432.CCR-12-2189.

23. Yang J, Mao M, Zhang S, Li H, Jiang Z, Cao G, Cao D, Wang $\mathrm{X}$, Zhang L. Innate defense regulator peptide synergizes with CpG ODN for enhanced innate intestinal immune responses in neonate piglets. Int Immunopharmacol. 2012; 12: 415-24. doi: 10.1016/j.intimp.2011.12.015.

24. Cao D, Li H, Jiang Z, Cheng Q, Yang Z, Xu C, Cao G, Zhang L. CpG oligodeoxynucleotide synergizes innate defense regulator peptide for enhancing the systemic and mucosal immune responses to pseudorabies attenuated virus vaccine in piglets in vivo. Int Immunopharmacol. 2011; 11: 748-54. doi: 10.1016/j.intimp.2011.01.028.

25. Kindrachuk J, Jenssen H, Elliott M, Townsend R, Nijnik A, Lee SF, Gerdts V, Babiuk LA, Halperin SA, Hancock RE. A novel vaccine adjuvant comprised of a synthetic innate defence regulator peptide and $\mathrm{CpG}$ oligonucleotide links innate and adaptive immunity. Vaccine. 2009; 27: 4662-71. doi: 10.1016/j.vaccine.2009.05.094.

26. Yu CH, Luo ZC, Li M, Lu L, Li Z, Wu XZ, Fan YZ, Zhang HL, Zhou BL, Wan Y, Men K, Tian YM, Chen S, et al. Synthetic innate defense regulator peptide combination using $\mathrm{CpG}$ ODN as a novel adjuvant induces longlasting and balanced immune responses. Mol Med Rep. 2016; 13: 915-24. doi: 10.3892/mmr.2015.4581.

27. Torre LA, Bray F, Siegel RL, Ferlay J, Lortet-Tieulent J, Jemal A. Global cancer statistics, 2012. CA Cancer J Clin. 2015; 65: 87-108. doi: 10.3322/caac.21262.

28. Sugita Y, Wada H, Fujita S, Nakata T, Sato S, Noguchi Y, Jungbluth AA, Yamaguchi M, Chen YT, Stockert E, Gnjatic S, Williamson B, Scanlan MJ, et al. NY-ESO-1 expression and immunogenicity in malignant and benign breast tumors. Cancer Res. 2004; 64: 2199-204.

29. Dhodapkar MV, Sznol M, Zhao B, Wang D, Carvajal RD, Keohan ML, Chuang E, Sanborn RE, Lutzky J, Powderly J, Kluger H, Tejwani S, Green J, et al. Induction of antigenspecific immunity with a vaccine targeting NY-ESO-1 to the dendritic cell receptor DEC-205. Sci Transl Med. 2014; 6: 232ra51. doi: 10.1126/scitranslmed.3008068.

30. Jungbluth AA, Chen YT, Stockert E, Busam KJ, Kolb D, Iversen K, Coplan K, Williamson B, Altorki N, Old LJ. Immunohistochemical analysis of NY-ESO-1 antigen expression in normal and malignant human tissues. Int $\mathrm{J}$ Cancer. 2001; 92: 856-60. doi: 10.1002/ijc.1282.

31. Hilchie AL, Wuerth K, Hancock RE. Immune modulation by multifaceted cationic host defense (antimicrobial) peptides. Nat Chem Biol. 2013; 9: 761-8. doi: 10.1038/nchembio.1393.

32. Banchereau J, Briere F, Caux C, Davoust J, Lebecque S, Liu YJ, Pulendran B, Palucka K. Immunobiology of dendritic cells. Annu Rev Immunol. 2000; 18: 767-811. doi: 10.1146/ annurev.immunol.18.1.767.

33. Lim EJ, Lee SH, Lee JG, Kim JR, Yun SS, Baek SH, Lee C. Toll-like receptor 9 dependent activation of MAPK and NF-kB is required for the $\mathrm{CpG}$ ODN-induced matrix metalloproteinase-9 expression. Exp Mol Med. 2007; 39: 239-45. doi: 10.1038/emm.2007.27.

34. Amcheslavsky A, Bar-Shavit Z. Interleukin (IL)-12 mediates the anti-osteoclastogenic activity of CpGoligodeoxynucleotides. J Cell Physiol. 2006; 207: 244-50. doi: 10.1002/jcp.20563.

35. Babolewska E, Brzezinska-Blaszczyk E. Humanderived cathelicidin LL-37 directly activates mast cells to proinflammatory mediator synthesis and migratory response. Cell Immunol. 2015; 293: 67-73. doi: 10.1016/j. cellimm.2014.12.006.

36. Kool M, Fierens K, Lambrecht BN. Alum adjuvant: some of the tricks of the oldest adjuvant. J Med Microbiol. 2012; 61: 927-34. doi: 10.1099/jmm.0.038943-0.

37. Vivier E, Tomasello E, Baratin M, Walzer T, Ugolini S. Functions of natural killer cells. Nat Immunol. 2008; 9: 503-10. doi: 10.1038/ni1582.

38. Mentlik James A, Cohen AD, Campbell KS. Combination immune therapies to enhance anti-tumor responses by NK cells. Front Immunol. 2013; 4: 481. doi: 10.3389/ fimmu.2013.00481.

39. Schettini J, Kidiyoor A, Besmer DM, Tinder TL, Roy LD, Lustgarten J, Gendler SJ, Mukherjee P. Intratumoral delivery of CpG-conjugated anti-MUC1 antibody enhances NK cell anti-tumor activity. Cancer Immunol Immunother. 2012; 61: 2055-65. doi: 10.1007/s00262-012-1264-y.

40. Long EO. Tumor cell recognition by natural killer cells. Semin Cancer Biol. 2002; 12: 57-61. doi: 10.1006/scbi.2001.0398.

41. Matsumoto M, Tatematsu M, Nishikawa F, Azuma M, Ishii N, Morii-Sakai A, Shime H, Seya T. Defined TLR3-specific adjuvant that induces NK and CTL activation without significant cytokine production in vivo. Nat Commun. 2015; 6: 6280. doi: 10.1038/ncomms7280.

42. Huo W, Ye J, Liu R, Chen J, Li Q. Vaccination with a chaperone complex based on PSCA and GRP170 adjuvant enhances the CTL response and inhibits the tumor growth in mice. Vaccine. 2010; 28: 6333-7. doi: 10.1016/j.vaccine.2010.06.093.

43. Xu Z, Ramishetti S, Tseng YC, Guo S, Wang Y, Huang L. Multifunctional nanoparticles co-delivering Trp2 peptide and $\mathrm{CpG}$ adjuvant induce potent cytotoxic T-lymphocyte response against melanoma and its lung metastasis. J Control Release. 2013; 172: 259-65. doi: 10.1016/j. jconrel.2013.08.021.

44. Kidd P. Th1/Th2 balance: the hypothesis, its limitations, and implications for health and disease. Altern Med Rev. 2003; 8: 223-46.

45. Mandal-Ghosh I, Chattopadhyay U, Baral R. Neem leaf preparation enhances Th1 type immune response and 
anti-tumor immunity against breast tumor associated antigen. Cancer Immun. 2007; $7: 8$.

46. Jerome KR, Sloan DD, Aubert M. Measurement of CTLinduced cytotoxicity: the caspase 3 assay. Apoptosis. 2003; 8: 563-71. doi: 10.1023/A:1026123223387.

47. Iida S, Kuni-Kamochi R, Mori K, Misaka H, Inoue M, Okazaki A, Shitara K, Satoh M. Two mechanisms of the enhanced antibody-dependent cellular cytotoxicity (ADCC) efficacy of non-fucosylated therapeutic antibodies in human blood. BMC Cancer. 2009; 9: 58. doi: 10.1186/1471-2407-9-58.
48. Mabuka J, Nduati R, Odem-Davis K, Peterson D, Overbaugh J. HIV-specific antibodies capable of ADCC are common in breastmilk and are associated with reduced risk of transmission in women with high viral loads. PLoS Pathog. 2012; 8: e1002739. doi: 10.1371/journal. ppat.1002739.

49. Lu Y, Wei YQ, Tian L, Zhao X, Yang L, Hu B, Kan B, Wen YJ, Liu F, Deng HX, Li J, Mao YQ, Lei S, et al. Immunogene therapy of tumors with vaccine based on xenogeneic epidermal growth factor receptor. J Immunol. 2003; 170: 3162-70. 